\title{
ARQUITETURA E CONSTRUÇÃO COM ANDAIMES ${ }^{1}$
}

\author{
Felipe de Paula Campolina ${ }^{2}$ \\ Tito Flávio Rodrigues de Aguiar ${ }^{3}$ \\ Ernani Carlos de Araújo ${ }^{4}$
}

DOI: 10.5752/P.2316-1752.2017v25n36p244

\section{Resumo}

Com as evoluções operadas ao longo dos anos, associadas a inúmeras experimentações de ordem prática, os andaimes vêm se tornando cada vez mais atraentes devido à grande flexibilidade que proporcionam. O nível tecnológico em que se encontram atualmente permite vislumbrar novas possibilidades de uso, como, por exemplo, a aplicação desses componentes para solução estrutural de edificações. Por meio de uma pesquisa exploratória, este artigo

\footnotetext{
1. Este artigo toma por base uma investigação feita por Felipe de Paula Campolina no Mestrado Profissional em Construções Metálicas (MECOM) da Escola de Minas da Universidade Federal de Ouro Preto (UFOP), sob a orientação do Prof. Dr. Tito Flávio Rodrigues de Aguiar e coorientação do Prof. Dr. Ernani Carlos de Araújo.

2. Arquiteto e urbanista pela Universidade FUMEC e mestrando do MECOM, Escola de Minas, UFOP. E-mail: fpcamp@gmail.com

3. Arquiteto e Urbanista e Doutor em História pela Universidade Federal de Minas Gerais (UFMG). Professor adjunto do Departamento de Arquitetura e Urbanismo (DEARQ), Escola de Minas, UFOP. E-mail: tito.aguiar@em.ufop.br

4. Engenheiro civil pela UFOP, Mestre e Doutor em Engenharia Civil pela Universidade de São Paulo. Professor associado do Departamento de Engenharia Civil (DECIV), Escola de Minas, UFOP. E-mail: ernanidearaujo@yahoo.com.br
} 
aborda os principais sistemas utilizados nesse novo contexto e apresenta exemplos práticos da produção contemporânea do gênero, avaliando e destacando suas principais características. Percebe-se que esse tipo de estrutura pode ser muito eficiente em alguns casos, e que sua relação custo-benefício pode variar muito, dependendo das soluções de projeto adotadas.

Palavras-chave: Andaimes. Aço. Sistema construtivo. Inovação. Flexibilidade. 


\section{ARCHITECTURE AND CONSTRUCTION WITH SCAFFOLDING}

\section{Abstract}

With all the developments acquired over the last 100 years, by decades of continuous research, along with numerous practical experiments, these components are becoming increasingly attractive due to the great flexibility they provide to us. The technological level that they have already achieved allows us to experiment new ways of use, different from what we are used to see. This article intends to approach practical examples of the main characteristics of the contemporary production of buildings that have been using conventional scaffolding as a primary structure, evaluating and highlighting their main characteristics, as well presenting the most used types of scaffold systems in this new context. It can be seen that this type of structure can be very efficient in some cases, and that its cost-benefit ratio can vary widely depending on the design solutions adopted.

Keywords: Scaffolding. Steel. Construction system. Flexibility.
ARQUITECTURA Y CONSTRUCCIÓN CON ANDAMIOS

\section{Resumen}

Los andamios, como se conocen hoy, son fabricados con una finalidad aparentemente única, sirviendo como construcciones auxiliares provisionales en los canteros de obras. Con todos los desarrollos adquiridos en los últimos 100 años, junto con numerosos experimentos prácticos, estos componentes son cada vez más atractivos debido a la gran flexibilidad que nos brindan. El nivel tecnológico que este sistema ya ha alcanzado nos permite experimentar nuevas formas de uso, además de lo que estamos acostumbrados a ver. Se percibe que este tipo de estructura puede ser muy eficiente en algunos casos, y que su relación costo / beneficio puede variar mucho dependiendo de las soluciones de proyecto adoptadas.

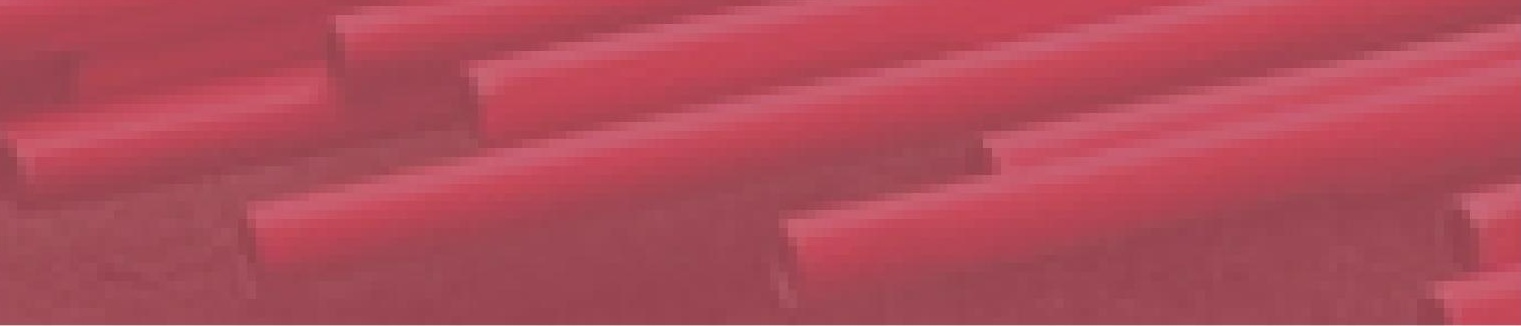




\section{Introdução}

A questão a ser abordada neste artigo diz respeito à evolução do uso dos tradicionais andaimes disponíveis no mercado e à criação de espaços arquitetônicos temporários e/ ou permanentes em situações nas quais esse componente esteja predominantemente inserido no contexto. Com a premissa de investigar e difundir esse uso diferenciado do andaime, a intenção é contribuir para um melhor entendimento desses componentes, conhecendo algumas das técnicas de conexão que fazem parte dessa tecnologia, bem como exemplos de aplicações, mostrando práticas de projeto e construção com esse sistema.

Segundo boas práticas da técnica, o andaime deve ser uma estrutura que pode ser montada e desmontada sem dificuldades, preferencialmente sem o auxílio de máquinas. 0 ideal é que o peso de cada componente não exceda $25 \mathrm{kgf}$ (250 N), para poder ser transportado e manuseado facilmente por apenas uma pessoa. Considerando isso e após o aperfeiçoamento decorrente do cálculo e das experiências práticas, a indústria tem geralmente adotado como peça básica dos andaimes o tubo de aço com diâmetro de $48,3 \mathrm{~mm}$ e parede com espessura de $3,2 \mathrm{~mm}$, com massa aproximadamente equivalente a $3,6 \mathrm{kgf}(36 \mathrm{~N})$ por metro linear. Com essas dimensões, pode-se considerar que um tubo de aço com seis metros de comprimento, que, de 
acordo com o padrão da indústria, é o comprimento máximo adotado, pesaria aproximadamente $22 \mathrm{kgf}(220 \mathrm{~N})$, estando dentro dos limites ideais de manuseabilidade (RAMOS FILHO, 2012).

Ao lidar com esse tipo de estrutura, a primeira grande questão é a escolha de qual andaime utilizar. Conforme mostrado, o sistema ideal deve ser leve e flexível para ser erguido de maneira rápida e inteligente. Porém, existem diversos tipos de andaimes com essas características e tal escolha pode não ser uma tarefa simples. De maneira geral, não existe regra pré-definida, tudo dependerá de condicionantes específicos em cada situação, tanto no âmbito executivo quanto no econômico. Na prática, em quase todos os casos, contratantes e construtores tendem a escolher $\mathrm{o}$ método mais barato disponível, desde que o andaime cumpra os requisitos de segurança e, ao mesmo tempo, se encaixe no escopo de trabalho (MARKS, 2016).

\section{Tipos mais utilizados para uma arquitetura com andaimes}

Neste artigo serão apresentados os dois sistemas de andaimes metálicos mais utilizados para elaborar obras arquitetônicas utilizando andaimes como elementos estruturais: o tubo e braçadeira e o multidirecional, destacando seus métodos de conexões e componentes essenciais. 
Tubo e braçadeira, do original inglês tube and clamp, é o pioneiro dos andaimes metálicos. Desenvolvido no início do século $X X$, ainda é amplamente utilizado em várias regiões do mundo, principalmente no Reino Unido, onde foi criado e onde seu uso permanece forte há mais de 100 anos. Segundo Viunov (2011), é o sistema mais versátil do mercado, constituído basicamente por tubos e braçadeiras metálicas, além de dezenas de componentes e acessórios complementares. Pode ser montado com inúmeras variações volumétricas, sendo extremamente flexível em qualquer plano espacial. A grande vantagem desse sistema, além do baixo custo inicial, é a liberdade modular que se pode obter ao posicionar as braçadeiras livremente em qualquer ponto do tubo. Isso permite a criação de pisos em qualquer nível e, ao mesmo tempo, a criação de vãos com qualquer modulação desejada, desde que compatíveis com a resistência dos tubos e com os carregamentos previstos.

Esse sistema certamente é o que possui menores restrições para uso estrutural e é o único em que um mesmo elemento (o tubo) é utilizado em todos os eixos espaciais (MARKS, 2016). E, pode-se dizer, é muito mais fácil fazer ajustes de projeto em campo com o andaime de tubo e braçadeira do que com qualquer outro sistema. Devido a essa flexibilidade, é o preferido para trabalhar com volumetrias curvas e irregulares, como cúpulas e abóbodas, por exemplo. 
Esse sistema é configurado a partir de um tubo metálico com 48,3 mm de diâmetro por 3,2 mm de espessura, que é empregado nos três elementos estruturais básicos: o poste, que se inicia a partir do solo ou de qualquer outra base rígida; a travessa, que une dois postes e serve de apoio para as plataformas de piso; e a longarina, que é inserida logo abaixo da travessa, conectando os postes longitudinalmente. Nesse sistema, respeitar a correta posição desses elementos horizontais é uma questão de segurança, pois, caso a braçadeira responsável por sustentar o piso falhe ou deslize, ainda encontrará suporte na longarina posicionada logo abaixo (VIUNOV, 2011). Em alguns casos, no lugar do tubo padrão, a longarina pode ser substituída por uma treliça metálica para suportar vãos ou cargas maiores (figura 1: $a, b)$.

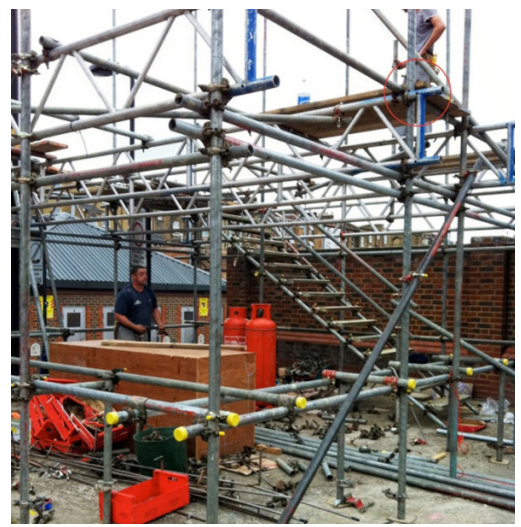

Figura 1a | Componentes estruturais básicos de uma estrutura de andaime formada pelo sistema tubo e braçadeira. Fonte: https://ridleys.org, adaptado pelo autor. 


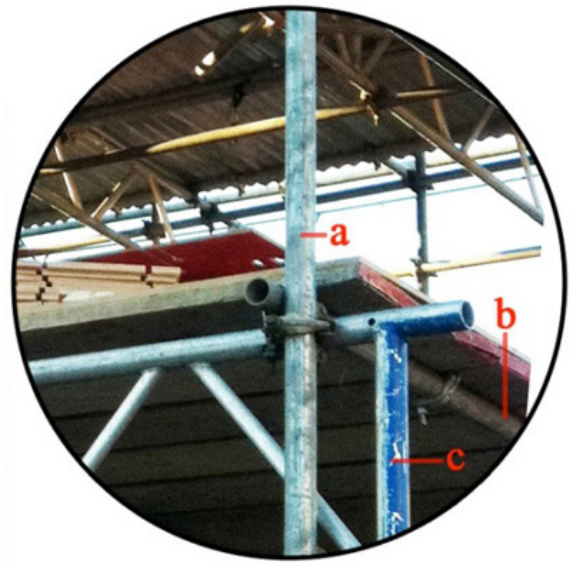

\author{
a- Poste (tubo metálico $Ø=48,3 \mathrm{~mm}$ ) \\ b- Travessa (tubo metálico $\emptyset=48,3 \mathrm{~mm}$ ) \\ C- Longarina (treliça metálica $\mathrm{h}=500 \mathrm{~mm}$ )
}

Figura 1b | Detalhe dos componentes estruturais básicos de uma estrutura de andaime formada pelo sistema tubo e braçadeira. Fonte: https://ridleys.org, adaptado pelo autor. 
Os três elementos estruturais básicos podem ser acoplados por braçadeiras fixas (figura 2a), que promovem uma união a $90^{\circ}$, formando assim um módulo básico que pode ser repetido sucessivamente nos planos horizontais e verticais para construir um andaime do tamanho e da forma que se desejar. Para dar a rigidez necessária à estrutura, são utilizadas diagonais, que são requisitadas principalmente no sentido longitudinal, em que a estrutura possui menor estabilidade. Esses elementos são feitos geralmente com o tubo de mesmo diâmetro externo $(48,3 \mathrm{~mm})$ e são conectados aos postes por meio de braçadeiras giratórias (figura 2b), ajustadas até $360^{\circ}$, permitindo pivotar o tubo livremente, de modo a unir os elementos em qualquer ângulo desejado. Apesar de não ser usual conectar dois tubos paralelamente, pode se utilizar também uma braçadeira paralela (fixa), que é mais resistente. Ao instalar uma diagonal, deve-se tomar o cuidado para manter a menor excentricidade possível, principalmente em situações com vários cruzamentos de tubo em um mesmo nó. É possível também conectar um tubo ao outro para ampliar o seu comprimento por meio de uma braçadeira de choque, chamada luva (figura 2c). Essas luvas não podem receber cargas de tração e a recomendação é fazê-las próximo ao nó, em uma distância máxima de $30 \mathrm{~cm}$. É possível também empregar conjuntamente tubos com diferentes diâmetros, sendo então necessário utilizar braçadeiras de redução, que existem em variados tamanhos (RAMOS FILHO, 2012). 

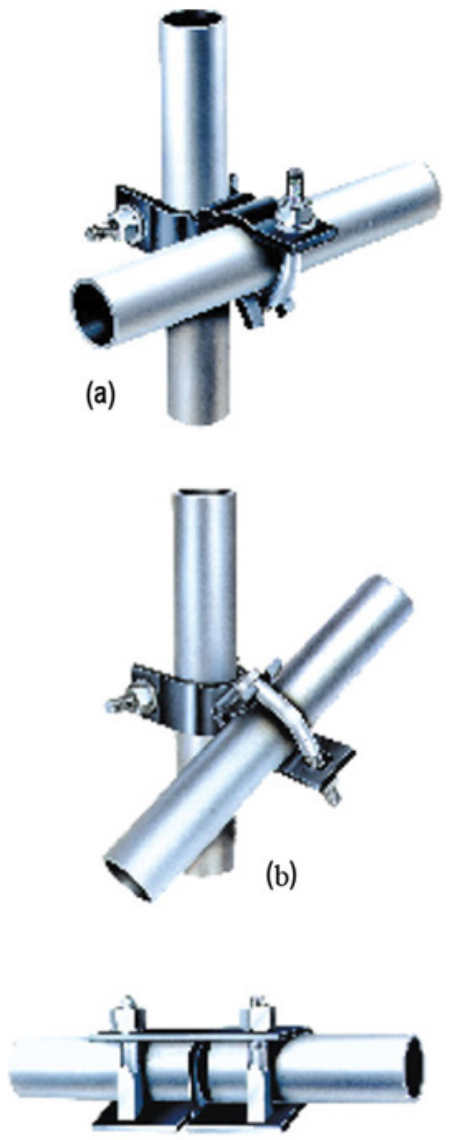

(c)

Figura 2 | Tipos de conectores mais comuns: (a) braçadeira fixa, (b) braçadeira giratória, (c) luva. Fonte: Rohr, catálogo tubular, ano 2008. 
A utilização desse sistema de andaimes demanda atenção especial às suas conexões, que possuem capacidade de carga relativamente reduzida se comparada aos outros sistemas, pois a transmissão dos esforços entre os tubos é feita por meio de atrito. A qualidade do material e as técnicas de fabricação das braçadeiras têm grande influência na capacidade estrutural. Em média, a braçadeira fixa é fabricada para suportar até 8,0 kN de carga e a giratória até 6,0 kN (RAMOS FILHO, 2012).

Pode-se dizer também que o sistema tubo e braçadeira é o que exige melhor técnica do montador, por isso não é o mais indicado para principiantes. A flexibilidade que o sistema oferece expõe o profissional a frequentes situações passíveis de erro, podendo tornar o processo de montagem mais demorado e oneroso. A montagem requer o auxílio de ao menos um ajudante, além de ferramentas auxiliares para aparafusar braçadeiras e aprumar corretamente os componentes. Como nesse sistema tubo e braçadeira utilizam-se componentes praticamente iguais, grande parte do tempo de planejamento e de montagem de andaimes pode ser consumida na organização dos tubos de acordo com os comprimentos, fator que deve ser considerado com cuidado.

O chamado sistema Multidirecional, introduzido no mercado há cerca de 50 anos, vem sendo predominante nos 
países mais desenvolvidos. Após décadas de aprimoramentos, pode ser considerado o sistema mais eficiente para a maioria dos usos, sendo capaz de minimizar atrasos e custos trabalhistas. Por isso vem tornando-se o modelo preferido pelos profissionais da área. Do termo original inglês modular system scaffolds, o primeiro exemplar do andaime multidirecional revolucionou a forma de montagem dessas estruturas, trazendo uma série de novos princípios e conceitos que ainda permanecem atuais. Nesse modelo, os dispositivos de conexões são previamente soldados nos postes de aço, formando esperas mais resistentes que as braçadeiras, tornando o poste apto a receber outros componentes, como travessas, longarinas e diagonais. Esses componentes, por sua vez, possuem suas extremidades adaptadas, com um sistema de estribos e pinças com chavetas autobasculantes que eliminam a necessidade de parafusos e porcas, dispensando o uso de ferramentas auxiliares durante a montagem.

O grande diferencial do sistema multidirecional é a capacidade de garantir a chamada "montagem lógica" da estrutura, sem riscos de distorções causadas por desalinhamentos eventuais. "Nesse termo, entende-se um tipo de construção que possibilita somente um único procedimento de montagem evitando erros de execução, garantindo os ângulos certos e não necessita de ferramentas especiais" (RAMOS FILHO, 2012, p. 157). 
O sistema modular multidirecional é constituído basicamente por três componentes básicos. O poste é um perfil tubular metálico equipado com dispositivos fixos, que recebem as conexões dos demais elementos. Esses pontos de conexões são fixados por meio de solda, realizada em fábrica, e espaçados em intervalos equidistantes, geralmente a cada $50 \mathrm{~cm}$. Os conectores podem possuir formatos variados, tais como estribo, roseta, copo, entre outros, variando de acordo com o princípio de acoplamento adotado. Essas conexões multidirecionais possuem alta rigidez nas juntas, que o permite suportar mais cargas e, também, atingir alturas maiores com mais segurança. Os limites máximos de cargas variam de acordo com cada fabricante, sendo imprescindível solicitar o manual do produto ao fabricante ao se projetar qualquer tipo de estrutura com andaime multidirecional.

A travessa e a longarina, componentes horizontais do sistema multidirecional, são dispostas no sentido transversal e longitudinal, respectivamente. Ao contrário do sistema de braçadeiras, o processo de conexão do andaime multidirecional permite que esses dois elementos fiquem alinhados no mesmo nível, evitando excentricidades indesejáveis na estrutura. Por outro lado, esses componentes possuem tamanhos fixos, pré-estabelecidos pelos fabricantes, que muitas vezes podem ser incompatíveis com as demandas de projeto, principalmente quando se busca montar estru- 
turas atípicas. Por fim, a diagonal, componente com dimensões fixas pré-estabelecidas pelos fabricantes, assim como os elementos horizontais, também restringe a aplicação do sistema a determinadas modulações (figura 3).
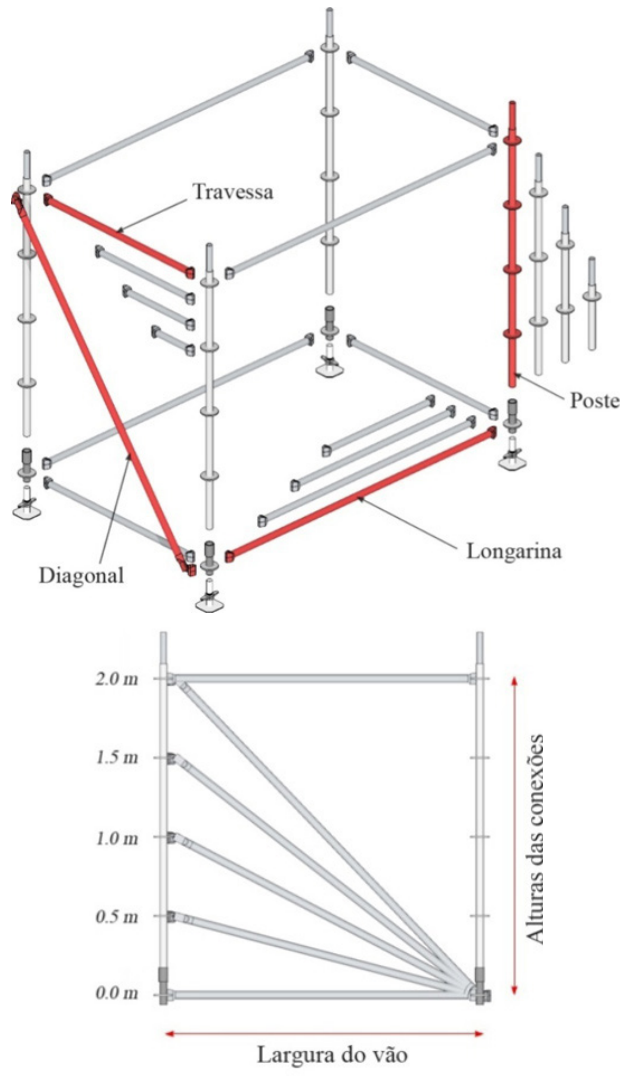

Figura 3 | Componentes básicos de uma estrutura formada pelo sistema multidirecional. Fonte: Imagem elaborada pelo autor. 
A maioria dos componentes do sistema multidirecional é fabricada com tubos de aço estrutural de alta resistência com diâmetro externo de 48,3 mm por 3,2 mm de espessura, tornando-o plenamente compatível com o andaime de tubo e braçadeira convencional (figura 4: a, b). Essa combinação entre dois sistemas é uma alternativa que potencializa as capacidades do andaime multidirecional, pois, além de fornecer um reforço estrutural extra, abre maior leque de soluções volumétricas possíveis de serem alcançadas. Sem esse recurso, projetar estruturas com volumetrias atípicas exclusivamente com elementos do sistema multidirecional pode ser extremamente difícil.

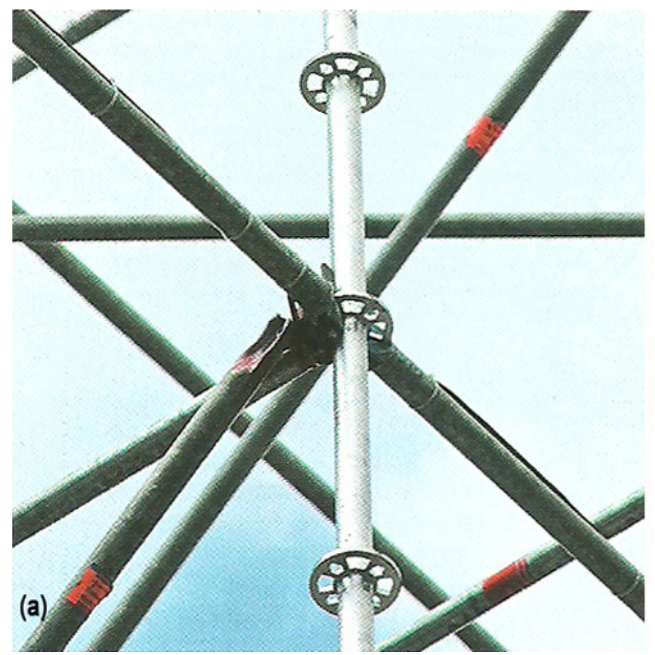

Figura 4a | Andaime multidirecional, trecho utilizando apenas componentes do sistema. Fonte: DETAIL 10/2013 - Temporary Structures (HELBIG, JUNGJOHANN e OPPE). 


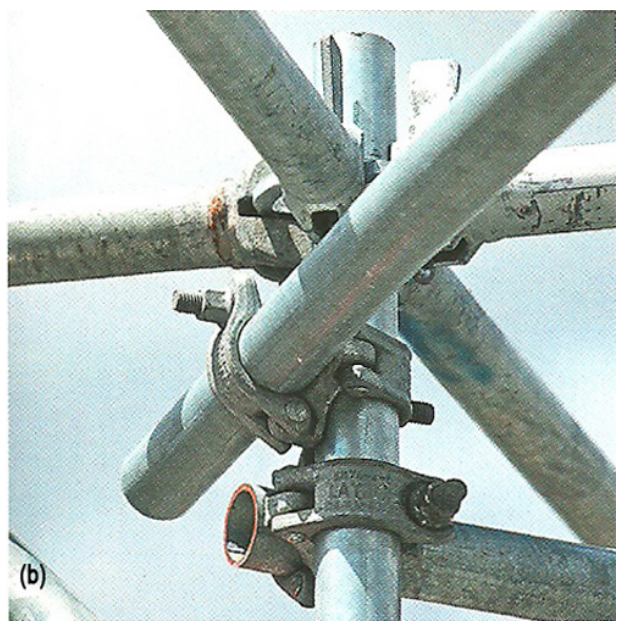

Figura 4b | Andaime multidirecional, trecho associado com o sistema de tubo e braçadeira. Fonte: DETAIL 10/2013 - Temporary Structures (HELBIG, JUNGJOHANN e OPPE).

Antes de qualquer decisão, é interessante sempre consultar a gama de dimensionamento dos três componentes principais do sistema multidirecional. Os fabricantes que oferecem uma maior variedade de medidas permitem ao projetista alcançar maior número de soluções volumétricas sem haver necessidade de associar o sistema multidirecional com outro tipo de andaime.

Utilizando exclusivamente andaimes multidirecionais, é possível preparar mão de obra para a montagem dos componentes com pouco tempo de treinamento prático. Comparado a outros sistemas que não aplicam o conceito de 
montagem lógica, os componentes do andaime multidirecional são montados segundo princípios simples e eficientes, que fazem da sua montagem um processo rápido e fácil. Em geral, para erguer uma estrutura básica, esse sistema requer um número de peças significantemente menor por metro, se comparado a outros sistemas de andaimes. Considerando os processos de planejamento e projeto, desde que estabelecidos corretamente, o andaime multidirecional pode ser montado em qualquer superfície com $30 \%$ a $50 \%$ a mais de rapidez do que o sistema de tubo e braçadeira, e pode reduzir o peso global da estrutura em até 25\% (MARKS, 2016).

Do ponto de vista econômico, o investimento inicial para aquisição de um andaime multidirecional é certamente mais alto do que o de outros sistemas. Consequentemente, seu aluguel também se torna mais oneroso. No entanto, os custos adicionais nesse investimento inicial podem ser mais do que compensados ao longo do tempo por meio da economia com material e mão de obra (MARKS, 2016).

Existem diversos modelos de andaimes multidirecionais. Alguns dos principais tipos disponíveis e suas peculiaridades serão abordados a seguir. Dentre os diversos formatos dos conectores multidirecionais existentes, destaca-se 0 modelo de roseta, também conhecido como ringlock. Esse modelo possui o nó central de conexão em formato de dis- 
co perfurado, permitindo acoplar simultaneamente até oito componentes, de forma que todos os membros horizontais e diagonais possam ser instalados em torno do poste. Esse recurso pode ser muito prático para a construção de volumetrias circulares. Nos modelos atuais, geralmente se encontram oito perfurações no disco, sendo quatro delas propositalmente mais estreitas para instalar os componentes horizontais em ângulos de $90^{\circ}$ da maneira mais precisa possível. As outras quatro aberturas existentes são mais largas, permitindo ajustes mais livres, em ângulos múltiplos de $15^{\circ}$. Nota-se no detalhe a seguir que esses ajustes só poderão acontecer quando não houver nenhum elemento adjacente instalado, caso contrário o ângulo será invariavelmente $45^{\circ}$. Os desenhos desses dispositivos variam de acordo com cada fabricante, sendo possível encontrar modelos em que os furos possuem configurações diferentes (figura 5).

Nesse modelo, o tubo dos elementos horizontais e diagonais possui as extremidades adaptadas em forma de cunha, com uma chaveta especial que bloqueia a ligação ao se deslizar sobre as perfurações do disco (figura 6). Após conectar as extremidades do tubo aos anéis, é necessário apenas um golpe simples de martelo sobre essa peça para deixar a conexão estruturalmente rígida. O mesmo processo é realizado para a desmontagem, porém no sentido inverso. 

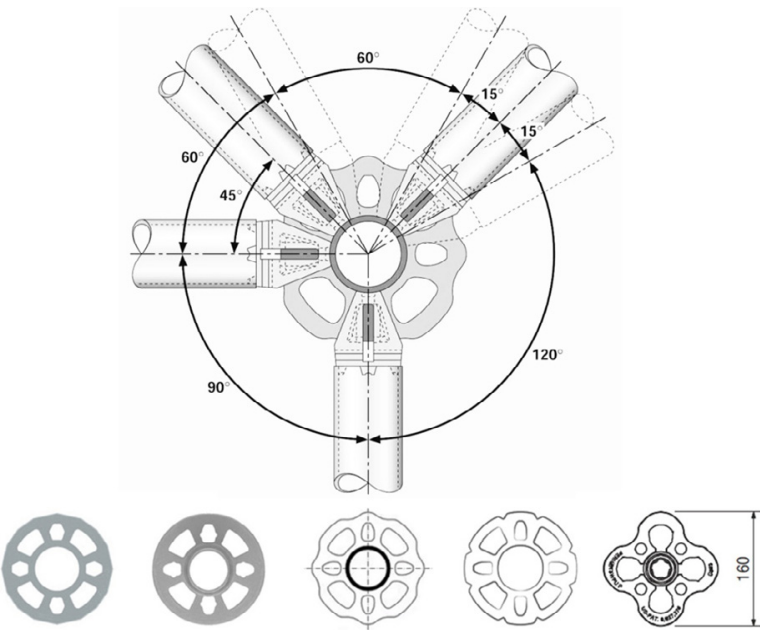

doka

Layher
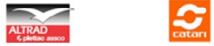

(PERI

Figura 5 | Detalhe dos ângulos e conexões possíveis da roseta do sistema Plettac Contur (acima) e variações dos desenhos de alguns dos principais fabricantes (abaixo). Fonte: Elaborado pelo autor a partir dos catálogos dos respectivos fabricantes.

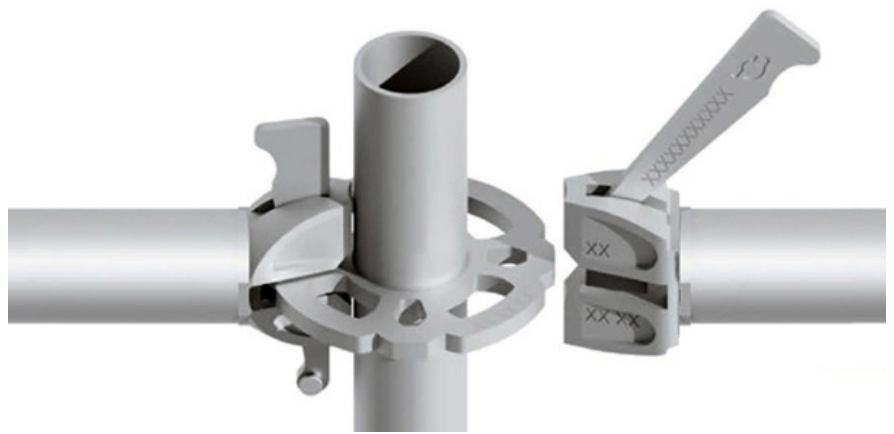

Figura 6 | Ringlock: detalhe da extremidade do tubo horizontal, com a chaveta de auto bloqueio. Fonte: http://www.catari.pt 
Procurando compreender o uso do andaime como solução construtiva, serão apresentados a seguir exemplos de obras arquitetônicas realizadas com a incorporação dos sistemas aqui apresentados, ou seja, da aplicação de andaimes como elementos estruturais. Nessa abordagem, destacam-se as principais características e métodos utilizados, refletindo sobre as lacunas existentes para esses sistemas se consolidarem como método alternativo de construção e discutindo o papel do arquiteto nesses processos.

\section{Repensando a função dos andaimes}

Uma das vantagens de trabalhar com os andaimes é a flexibilidade projetual que o sistema pode oferecer; mesmo com o uso quase que exclusivamente de barras ortogonais, há a liberdade de criação de um número ilimitado de configurações espaciais, desde um grid tridimensional simples a volumetrias amórficas e balanços em várias escalas. Sua adaptabilidade é uma forte característica, podendo ser utilizada em diferentes apropriações, basta explorar a criatividade. Essas utilizações vão desde pequenos módulos a grandes pavilhões, passando por residências, escolas, escritórios, comércios, restaurantes, hotéis, alojamentos, entre outras infinidades de uso.

Segundo Robert Kronenburg (2007), arquitetura flexível consiste em construções que são projetadas para respon- 
der facilmente a mudanças ao longo de sua vida útil. Os benefícios desse conceito são consideráveis, pois podem permanecer em uso por mais tempo, uma vez que se adequam melhor à sua finalidade, atendendo à experiência e à intervenção do usuário. Aproveitar uma inovação técnica dessa natureza pode ser ainda econômica e ecologicamente mais viável.

Conforme as pesquisas continuam avançando, os sistemas de andaime vão se tornando mais eficientes e com maior variedade de opções disponíveis no mercado, contudo essas otimizações são quase sempre focadas para o uso tradicional, atendendo principalmente ao campo da construção civil e industrial, em que se concentra a maior demanda. De qualquer maneira, é interessante pensar como toda essa tecnologia já desenvolvida possibilita a criação de segmentos alternativos e outros tipos de espaços flexíveis de forma descomplicada. E por mais que pareça simples, é importante conhecer os conceitos a fundo para usá-los com propriedade desde a concepção inicial. Além disso, o sistema de andaime ainda não é muito ajustado para esse uso alternativo, seja temporário ou permanente; as soluções e os detalhamentos complementares de fechamento e cobertura passam a ser um escopo muito complexo no contexto geral.

É nesse momento que a função da arquitetura começa a 
fazer mais sentido, tornando-se extremamente necessária. Sabendo lidar bem com a concepção estrutural e as limitações de cada sistema, o papel do arquiteto vai muito além do objetivo de erguer a estrutura: seu trabalho supera a simples montagem de componentes, à medida em que consegue manipular de forma integrada todo o ambiente funcional para propiciar a melhor sensação e a utilização possível aos ocupantes e contempladores da forma e do espaço. A arquitetura deve estar consciente de seu entorno, precisa saber das implicações do impacto sobre uma área e de seu contexto geral. Essa compreensão dos sentidos de uso e ocupação é o que distingue a arquitetura da construção comum (MOURNING, 2016).

Um exemplo interessante para introduzir essa discussão sobre as novas potencialidades do andaime é o projeto Pump up the blue house, idealizado em 2007 pelo designer Hervé Paraponaris. É uma espécie de transição entre o uso convencional e o alternativo do andaime, uma vez que se aplica o sistema de forma semelhante ao canteiro de obras, porém com uma finalidade diferente. Segundo Paul O'Neill (2009), o propósito desse projeto foi trazer de volta os andaimes para o exterior da casa, localizada em um novo distrito urbano de Amsterdam, com o intuito de aumentar as dimensões do espaço durante um período temporário. Com a inserção do andaime, além da estrutura refletir o processo contínuo de construção que o próprio bairro se 
encontrava, praticamente dobrava a área útil do edifício, criando os espaços extras necessários para atender à demanda imediata de abrigar um centro de eventos no local, com shows, reuniões, exposições e performances durante seis meses. Ao final desse período, toda estrutura pode ser desmontada, devolvendo o aspecto original da edificação (figura 7).

$\mathrm{Na}$ maioria das vezes, esses espaços são erguidos para perdurarem apenas um determinado tempo, seja dias ou até mesmo anos. Essa condição de efemeridade acaba oferecendo uma liberdade extra para o projetista, que deve se beneficiar dessas condições excepcionais para explorar novas espacialidades e formas de ocupação. É importante saber condicionar o projeto utilizando a legislação a seu favor, enxergando o leque de opções que se abre ao ter a possibilidade de ser temporário, removível ou portátil.

O simples fato de não se apossar do espaço, podendo devolvê-lo sem marcas, preservando a sua forma nativa após o uso, muitas vezes vem acompanhado de benefícios, como, por exemplo, a permissão de ocupar locais proibidos para as edificações convencionais. No cenário ideal, uma edificação que venha a funcionar muito bem, mesmo que inicialmente pensada para ser temporária, pode chegar ao ponto de tornar-se definitiva espontaneamente. 

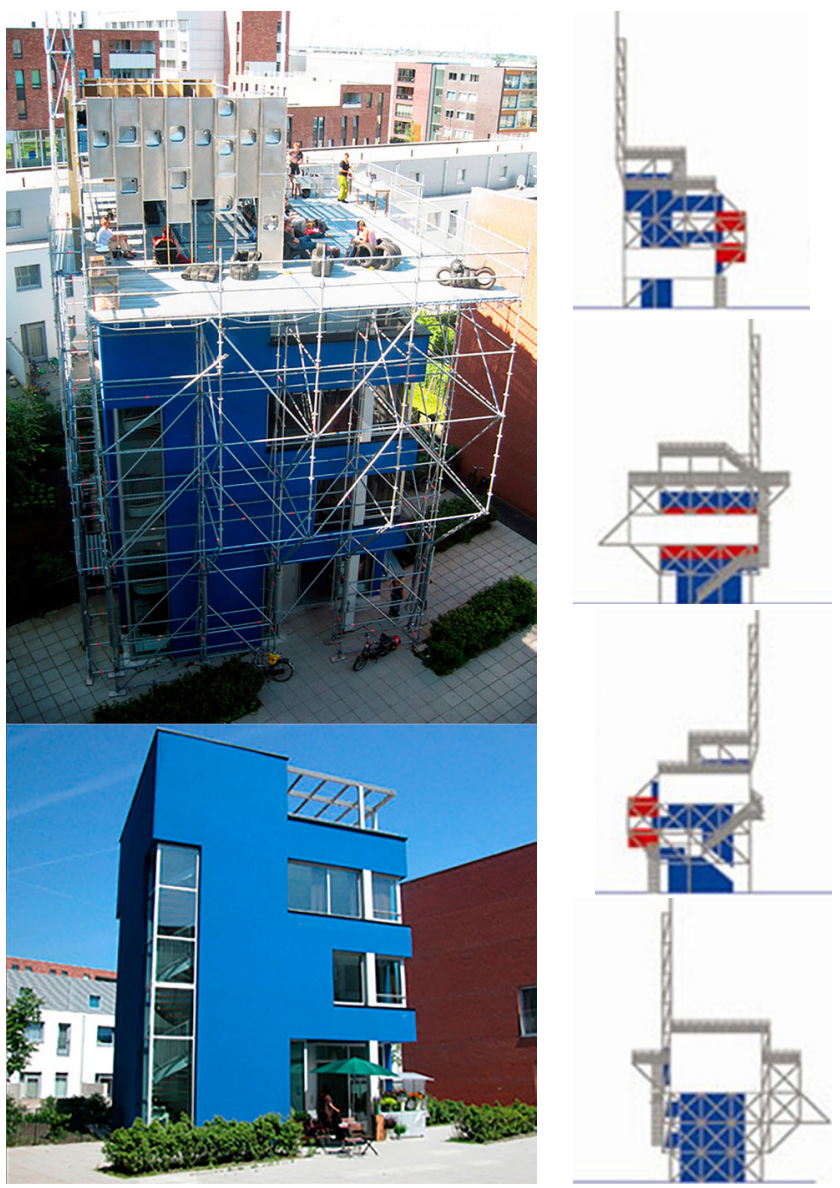

Figura 07 | Pump up the blue house, 2007- Andaime multidirecional acoplado à edificação convencional para acréscimo temporário de área útil. Ao final do período de uso, a edificação retoma sua forma original. Fonte: http://www.jeanneworks.net/projects/ the_blue_house/ 
A seguir, serão mostradas duas obras feitas com tipos diferentes de andaimes, que vão além do exemplo anterior, em que o andaime passa de coadjuvante a protagonista da obra, indo além de um mero suporte auxiliar para se tornar a estrutura principal da edificação.

Exemplo 1- Pavilhão-Escola Hamlet: Essa edificação passa inicialmente por duas fases bem distintas. Em um primeiro momento, teve seu protótipo instalado temporariamente no Museu de Arte Moderna de Louisiana, na Dinamarca, como parte da mostra África: Arquitetura, Cultura e Identidade, que ficou em cartaz de junho a outubro de 2015. Além de abrigar conteúdos da exposição, esse período de quatro meses serviu como teste para avaliar o desempenho geral dessa edificação antes de ser desmontada e exportada para o seu destino final. Em um segundo momento, a estrutura foi remontada no continente africano, onde passou a abrigar uma escola com aproximadamente $150 \mathrm{~m}^{2}$ de área útil, capaz de atender até 600 alunos de uma região carente do Quênia.

Mesmo com a implantação final sendo permanente, a edificação também precisava ser suficientemente flexível para ser desmontada e transportada de maneira eficiente. Com esse desafio, o arquiteto espanhol Jose Selgas, um dos responsáveis pelo projeto, teve como premissa o uso de materiais leves e duráveis, sobretudo de baixo custo. Após 
várias investigações, optou-se por um sistema construtivo pouco convencional, resolvido à base de andaimes de tubo e braçadeira associado a outros materiais de baixo custo, como telhas de policarbonato e chapas de OSB. Além de receber uma nova função, os tubos metálicos tradicionais ganharam uma nova pintura, conferindo um aspecto mais elegante para esse material (figura 8).

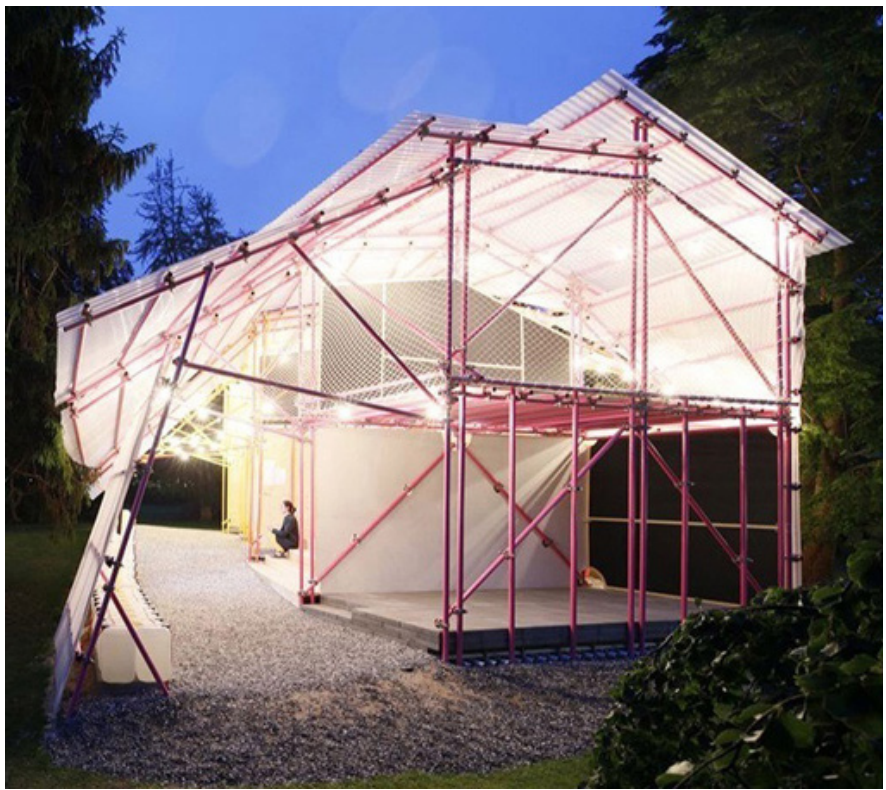

Figura 8a | Pavilhão-Escola Hamlet, 2015- Edificação permanente, sistema construtivo a partir de estrutura de andaime tubo e braçadeira. Fonte: http://www.archdaily. com/782058 


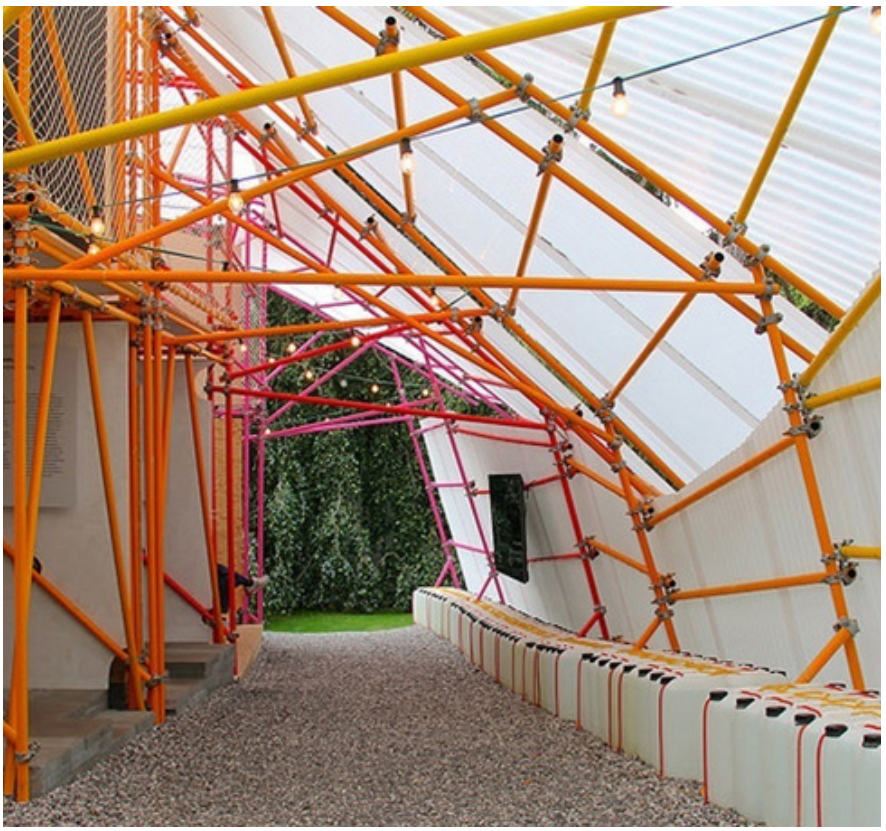

Figura 8b | Pavilhão-Escola Hamlet, 2015- Edificação permanente, sistema construtivo a partir de estrutura de andaime tubo e braçadeira. Fonte: http://www.archdaily. com/782058 
O espaço, resolvido em dois pavimentos, é composto por quatro blocos principais que abrigam as salas de aula. Cada módulo possui 4,64 metros de comprimento, 2,20 metros de largura e 5,61 metros de altura máxima, sendo inteiramente estruturado por andaimes de tubos e braçadeiras. Nessa concepção estrutural, a modulação dos postes segue um princípio semelhante ao sistema construtivo Light Steel Framing, criando uma espécie de gaiola em torno do espaço. Nesse caso, todas as extremidades foram reforçadas com postes duplos para distribuir melhor as cargas, visto que as braçadeiras são menos resistentes que o encaixe multidirecional. Interessante perceber que essa modulação tipo framing não segue para o segundo pavimento, onde a estrutura fica exposta a cargas menores. Em seguida foram inseridas diagonais em todas as laterais e fundos dos módulos, completando o travamento vertical. A estrutura da cobertura foi modulada com tubos, espaçados $80 \mathrm{~cm}$ em média, que avançam sobre a projeção da sala até se curvar sobre o solo, formando uma grande varanda (figura 9).

Por fim, os quatro blocos, dispostos lado a lado de forma irregular, são unificados por essa grande cobertura, criando um volume único que demonstra a potencialidade espacial do tubo e braçadeira. Internamente, recipientes plásticos cheios de água foram assentados na base dessa cobertura, ancorando o prédio ao chão e também servindo como bancos, dispostos ao redor da grande varanda (figura 10: a, b). 


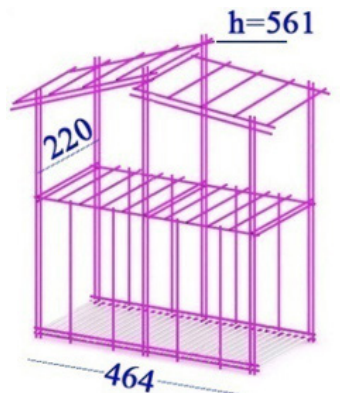

(a)

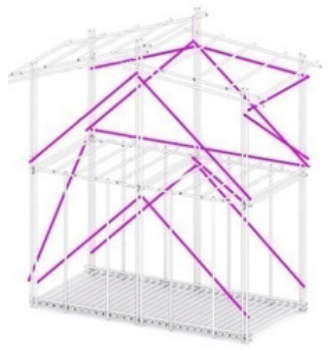

(b)

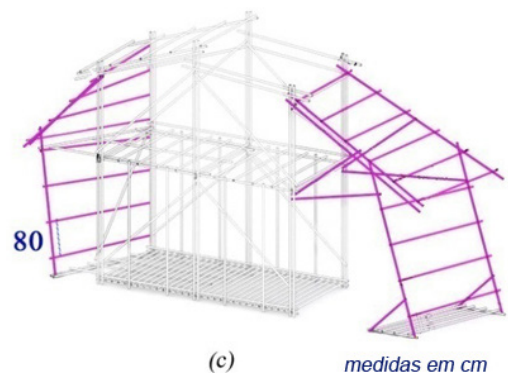

Figura 9 | Sequência de montagem do módulo mostrando, (a) o andaime aplicado como um sistema tipo framing, (b) os travamentos verticais e (c) o avanço da cobertura.

Fonte: http://arqa.com/en/architecture/kibera-hamlets-school.html, adaptado pelo autor. 


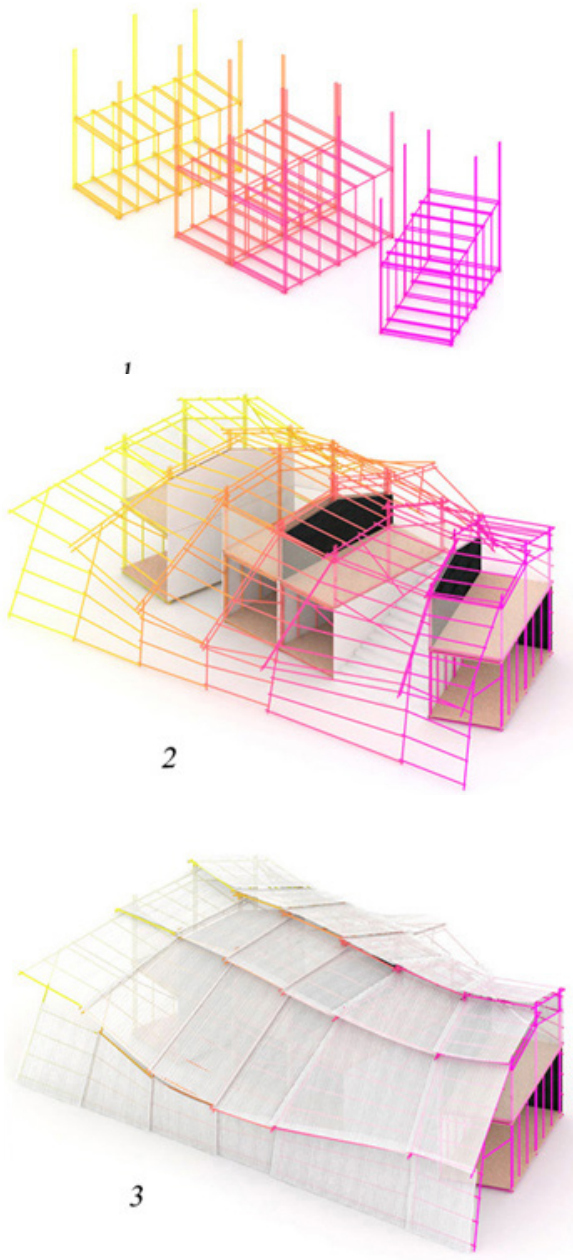

Figura 10a | Sequência de 1 a 3, mostrando a disposição dos módulos independentes, que são posteriormente unificados pela cobertura. Fonte: http://www.louisiana.dk 


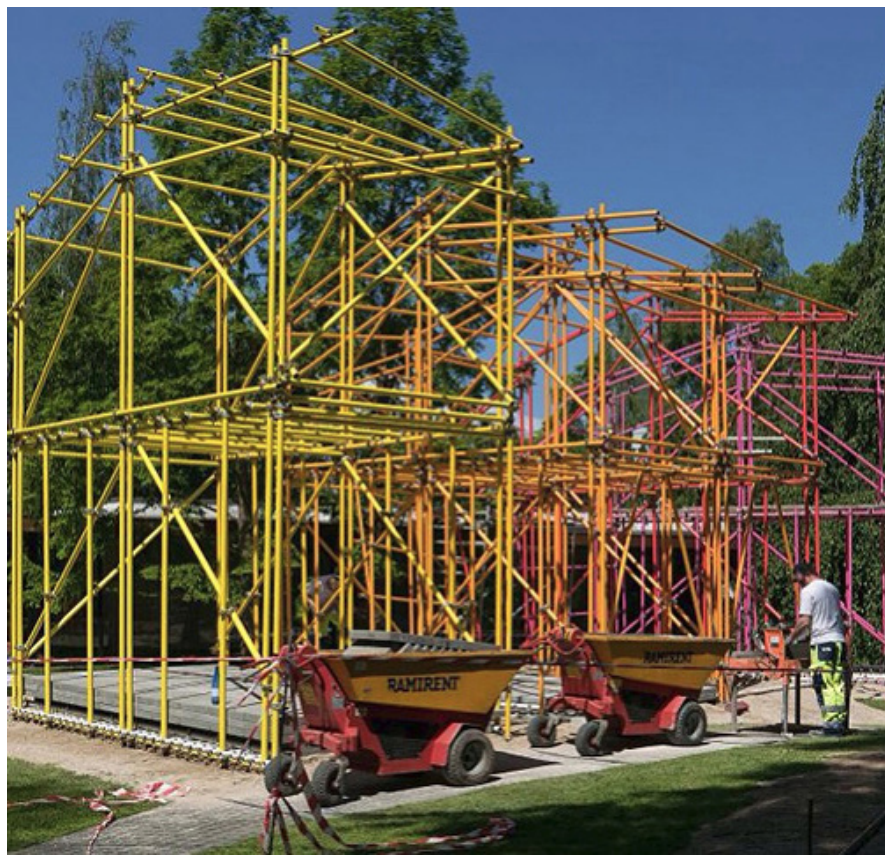

Figura 10b | Execução dos módulos com estrutura de andaimes. Fonte: http://www.louisiana.dk 


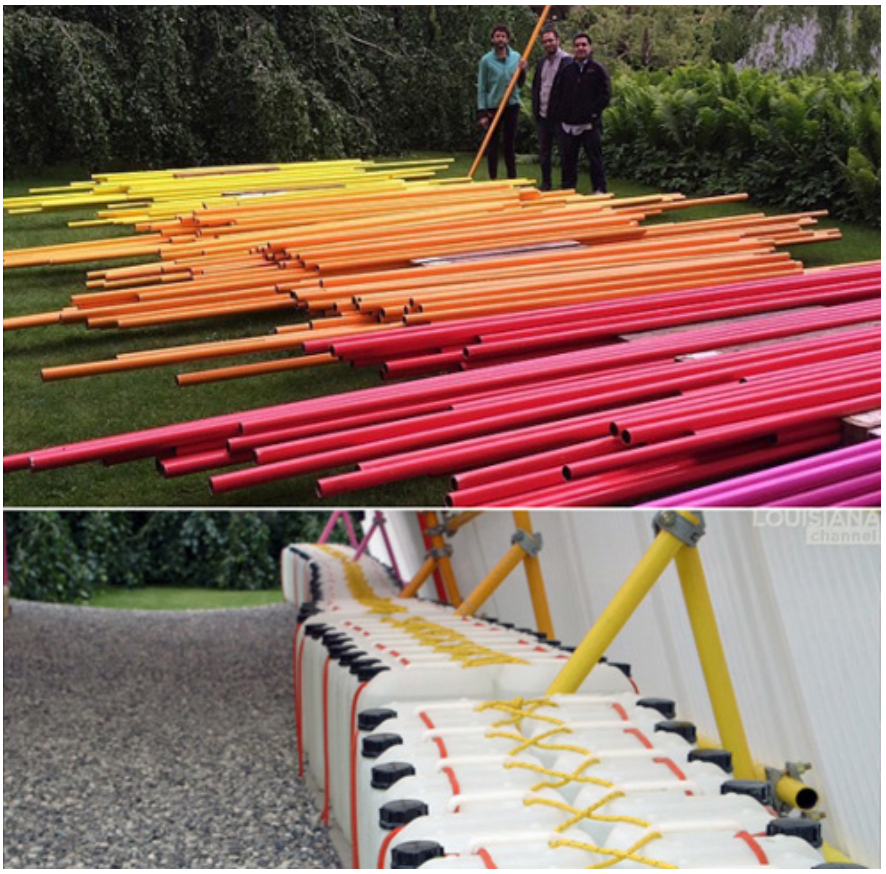

Figura 10c | Os tubos organizados antes do início da montagem e detalhe da solução de ancoragem com galões de água. Fonte: http://www.louisiana.dk 
Se comparado ao sistema multidirecional, esse tipo de andaime é infinitamente mais flexível na hora de projetar, uma vez que quase não possui restrições dimensionais, além de ser mais econômico financeiramente. Segundo o autor do projeto, essa edificação, que, além do andaime, utilizou somente materiais simples, teve o custo final aproximado de $\mathrm{R} \$ 110.000$ (£25.000), valor que representa algo em torno de $R \$ 750 / \mathrm{m}^{2}$.

Exemplo 2- Pousada Baubrasil (Studio Andaime): Localizada nos arredores de Tiradentes, em Minas Gerais, a pousada Baubrasil é um empreendimento que reúne um conjunto de habitações contemporâneas, oferecidas como opção de hospedagem aos visitantes que frequentam a região. São edificações executadas com diferentes métodos de construção rápida, tais como Light Steel Framing, CLT (Cross Laminated Timber), container e andaime.

Nesse projeto (figura 1: a, b), idealizado em 2013 pelo proprietário, foi utilizado o andaime multidirecional como sistema construtivo, sendo um exemplo prático que demonstra a flexibilidade desse material, que também pode ser implantado de forma permanente e em qualquer situação de topografia. Segundo o proprietário, durante o processo de montagem, foram gastas quatro semanas, trabalhando com uma equipe formada por quatro pessoas. A casa tem um pavimento e possui aproximadamente $65 \mathrm{~m}^{2}$ de área 
interna, além de $15 \mathrm{~m}^{2}$ de varanda externa, sendo totalmente estruturada por andaimes do tipo multidirecional de roseta (ringlock), fornecidos pela fabricante alemã Layher. Além da estrutura, a empresa forneceu os painéis de fechamento lateral, que podem ser conectados diretamente nas rosetas dos postes, realizando as vedações com chapas de policarbonato ou vidro.

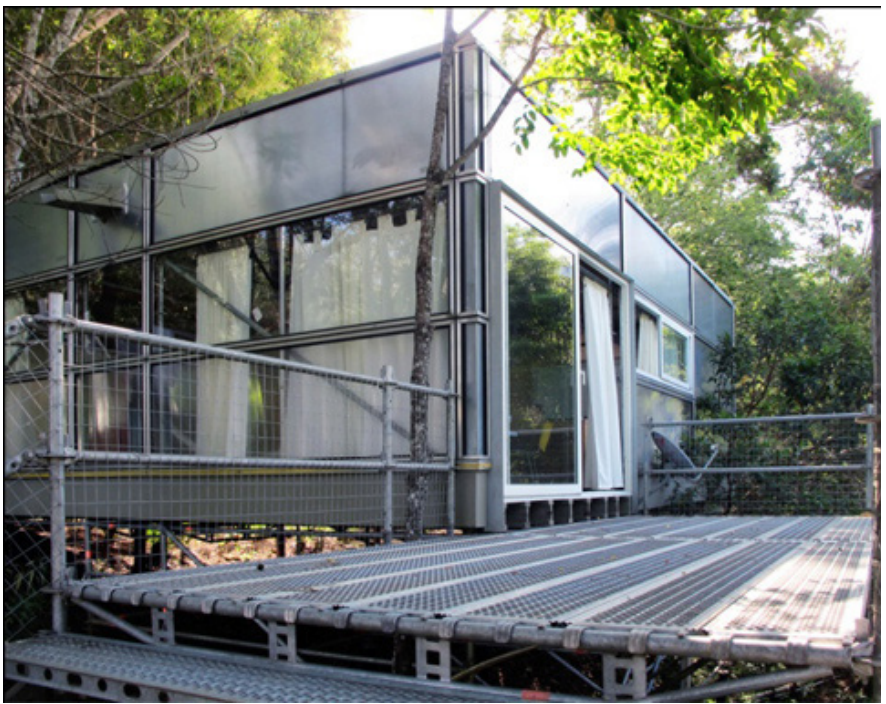

Figura 11a | Edificação permanente executada com estrutura de andaime multidirecional, implantada em um terreno acidentado. Fonte: Acervo do autor. 


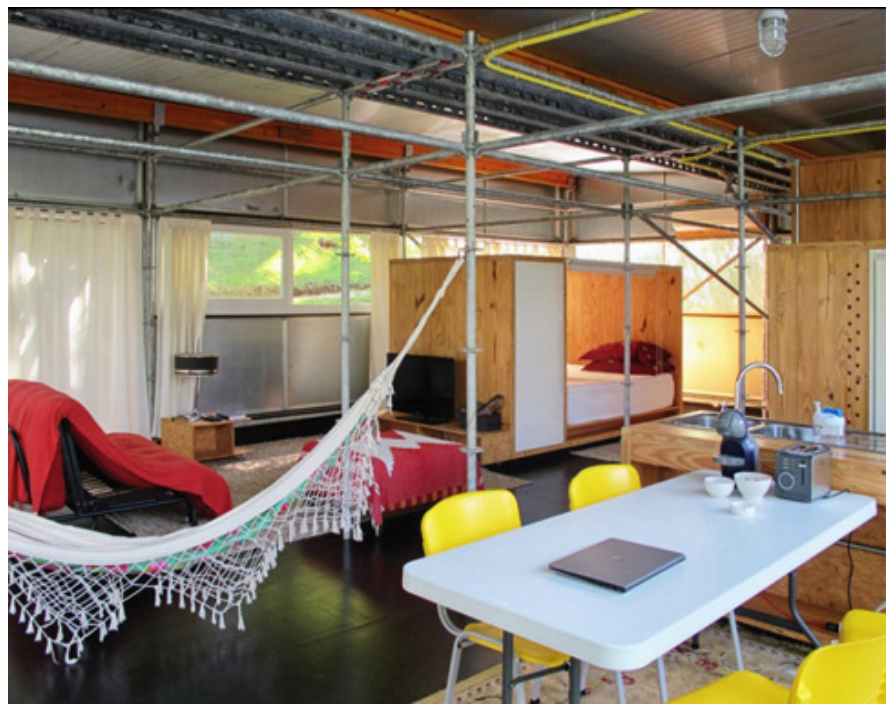

Figura 11b | Edificação permanente executada com estrutura de andaime multidirecional, implantada em um terreno acidentado. Fonte: Acervo do autor. 
O espaço interno é uma grande área com $921 \mathrm{~cm}$ por 723 cm de extensão, configurado a partir da repetição de um módulo-base com $307 \mathrm{~cm}$ de lado, e travados com diagonais verticais nas extremidades. Entre os módulos, há um espaçamento central de $109 \mathrm{~cm}$ de largura, dimensões procedentes das travessas do sistema. Externamente o módulo possui alturas que variam entre $350 \mathrm{~cm}$ a $650 \mathrm{~cm}$, devido à forte inclinação natural do terreno, superior a $40 \%$. Na varanda, a modulação utilizada foi de $307 \mathrm{~cm}$ por $257 \mathrm{~cm}$, sendo finalizada com uma escada feita de componentes próprios do sistema (figura 12: a, b, c).

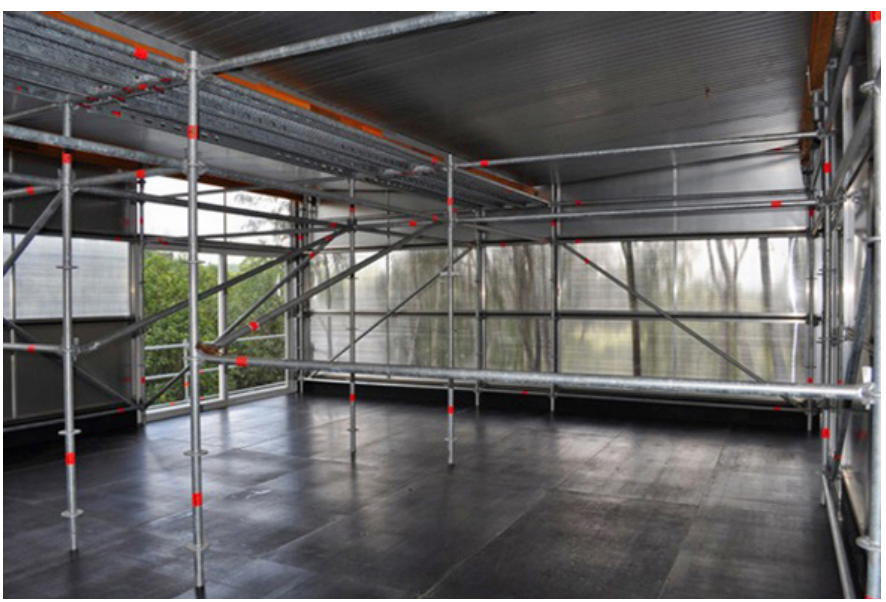

Figura 12a | Interior da edificação.

Fonte: http://www.studioveneziano.com.br/ 


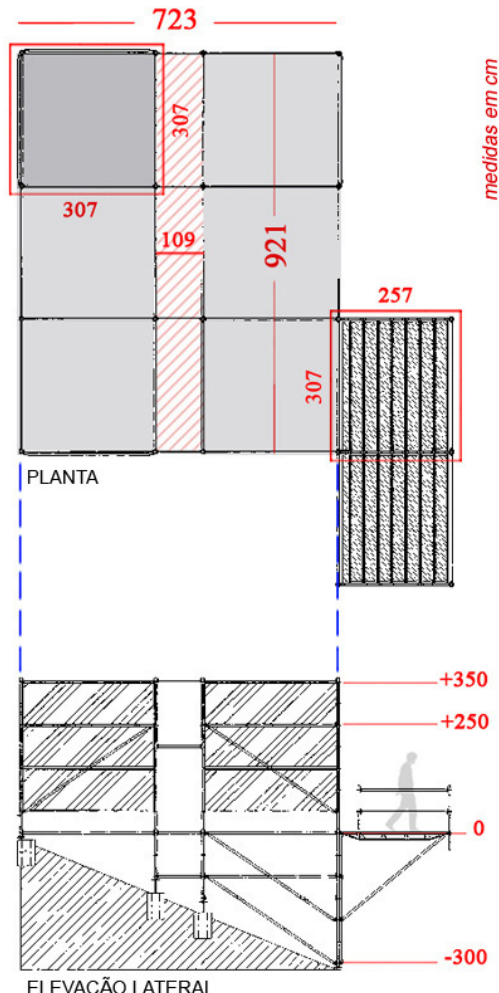

Figura 12b | Planta e elevação lateral da edificação, mostrando os módulos utilizados. Fonte: http://www.studioveneziano.com.br/ 


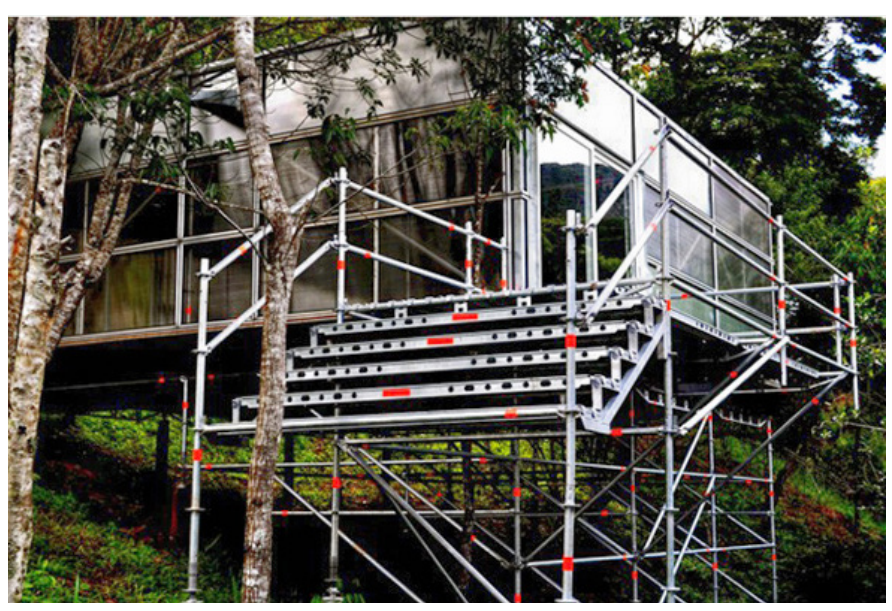

Figura 12c | Exterior da edificação.

Fonte: http://www.studioveneziano.com.br/ 
$\mathrm{O}$ piso interno e a cobertura foram estruturados com vigas $\mathrm{H} 20^{5}$ (figura 13: a, c), material leve e resistente, que geralmente são utilizadas para serviços de escoramento, e se adaptam muito bem ao sistema de andaime. Com $20 \mathrm{~cm}$ de altura, essas vigas vencem um vão máximo de $307 \mathrm{~cm}$, correspondente ao módulo-base. No piso ficam dispostas transversalmente a cada $40 \mathrm{~cm}$, e, por meio de um calço de madeira adaptado, ficam apoiadas diretamente em travessas reforçadas, feitas com a viga ponte do andaime multidirecional. Dessa forma, cria-se uma base para receber uma laje seca, feita com placas estruturais de OSB $18 \mathrm{~mm}$ sobre a viga de madeira. Acima dessas placas, foi instalado o piso final, feito com chapas de compensado plastificado na cor preta.

A cobertura possui duas águas e uma calha central, ficando sustentada por vigas $\mathrm{H} 20$ dispostas no sentido longitudinal da casa. Na extremidade, essas vigas estão apoiadas em forcados, instalados na parte superior do poste por meio de braçadeiras, e servem de suporte para fixar as telhas termoacústicas, na inclinação adequada ao escoamento das águas pluviais (figura 13: b, c). Internamente a divisão dos ambientes foi resolvida com caixotes de CLT, conferindo à estrutura um peso extra e deixando-a mais rígida e travada, de modo a evitar oscilações e vibrações (figura 13d). A 
fundação foi concebida de forma simples, utilizando estacas de eucalipto tratado, sem nenhum uso de concreto. Ao total são 20 estacas cravadas no solo, criando uma base sólida capaz de apoiar as sapatas ajustáveis para iniciar a montagem do andaime (figura13e). Apesar de permanente, essa construção é totalmente desmontável, inclusive a sua fundação é totalmente reversível, podendo ser extraída e reutilizada em outro local sem deixar marcas no terreno.

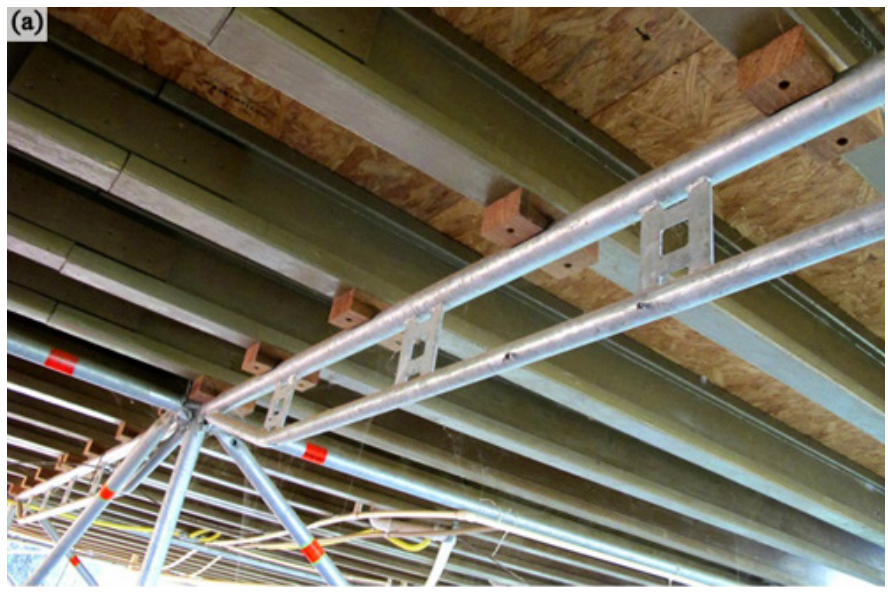

Figura 13a | Calço de madeira adaptado entre a viga ponte e as vigas H20. Fonte: Acervo do autor e http://www.studioveneziano.com.br/ 


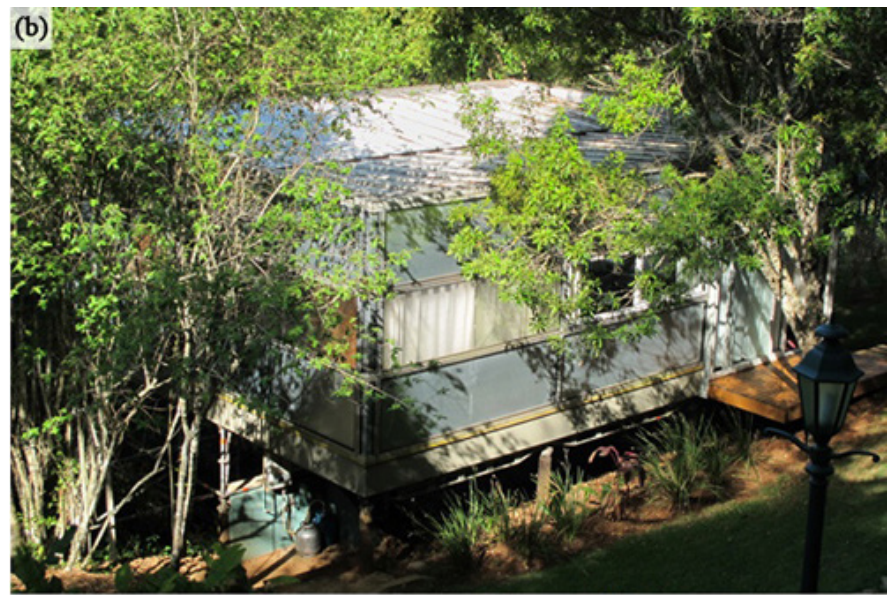

Figura 12b | Cobertura com duas águas com calha central. Fonte: Acervo do autor e http://www.studioveneziano.com.br/ 


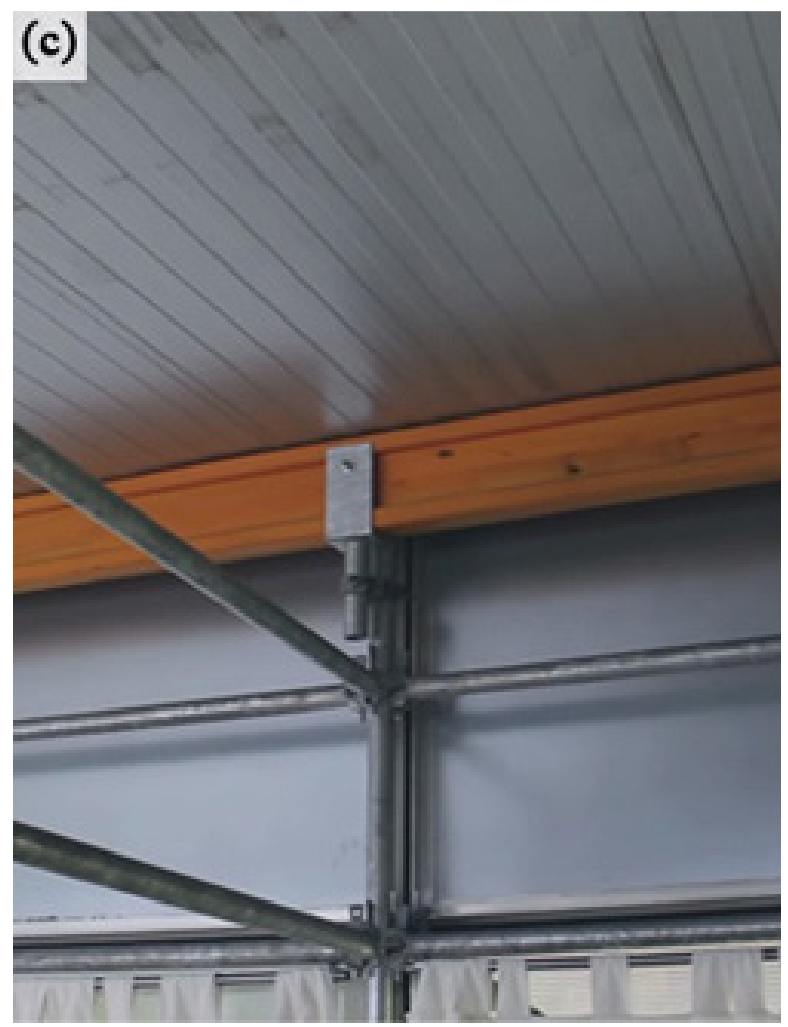

Figura 12c | Forcado metálico com a viga $\mathrm{H} 20$ que apoia as telhas sanduíche. Fonte: Acervo do autor e http://www.studioveneziano.com.br/ 


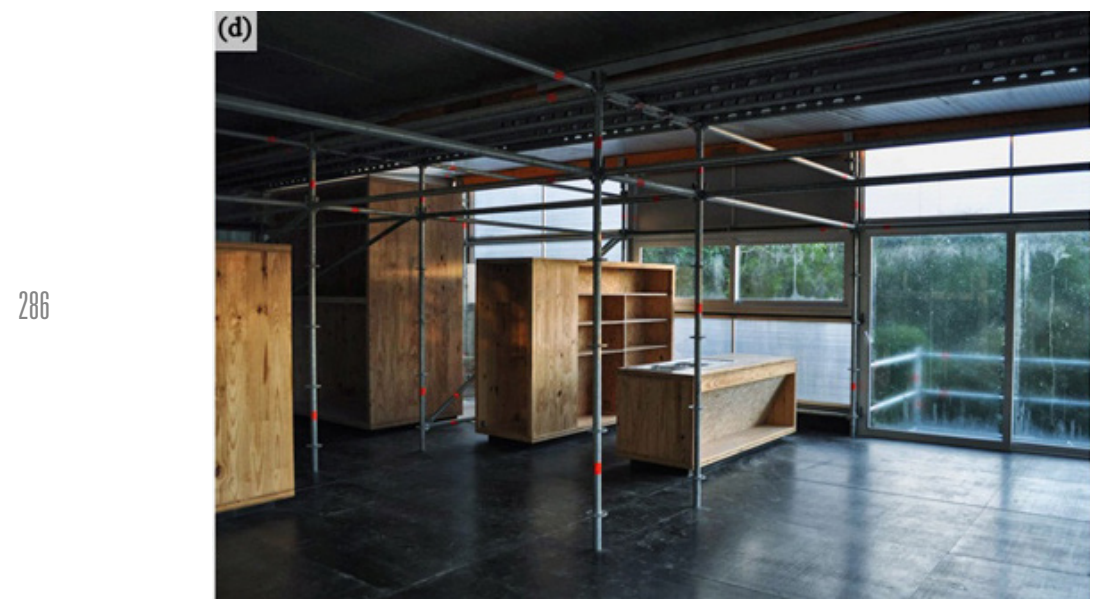

Figura 12d | Caixotes de CLT utilizados na divisão dos ambientes. Fonte: Acervo do autor e http://www.studioveneziano.com.br/ 


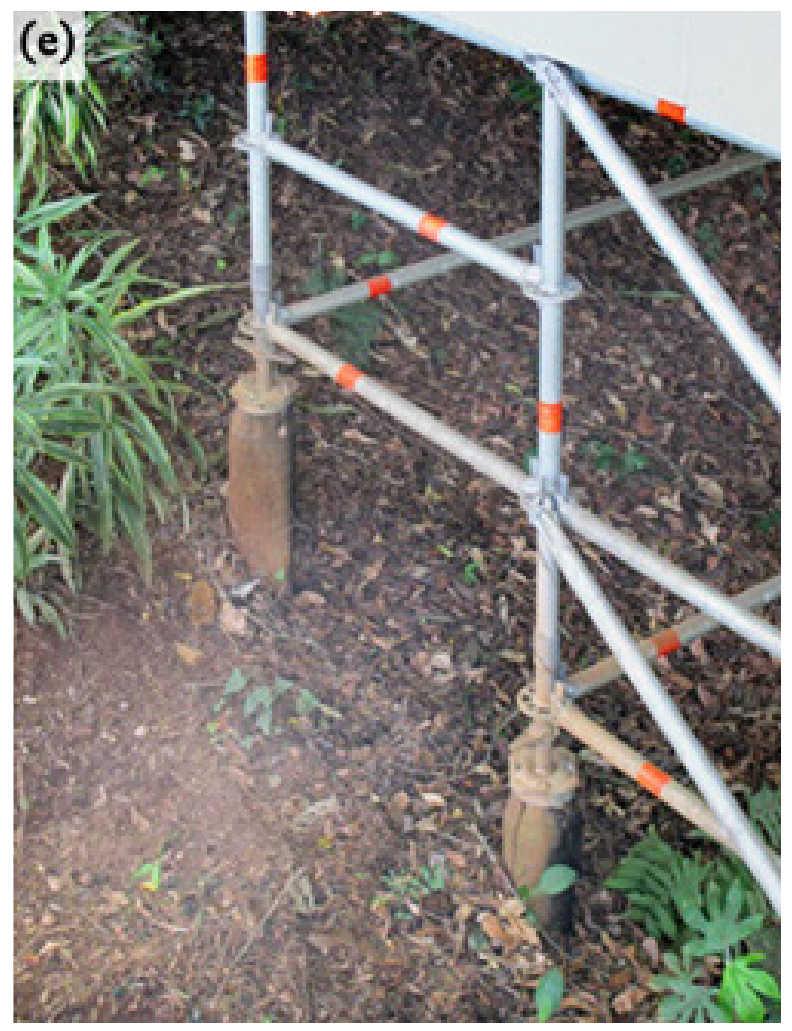

Figura 12e | Fundação com estaca de eucalipto.

Fonte: Acervo do autor e http://www.studioveneziano.com.br/ 
Além dos componentes principais do sistema, foram utilizadas plataformas metálicas de encaixe nos pisos externos e na parte central da cobertura, e painéis de vedação lateral, fornecidos pelo próprio fabricante do sistema de andaime. Segundo o proprietário, essa edificação teve o custo final aproximado de $R \$ 250.000$, correspondendo um valor próximo a $\mathrm{R} \$ 3.000 / \mathrm{m}^{2}$.

\section{Considerações finais}

Na última década, foi perceptível a presença de um movimento crescente no uso diferenciado do andaime, de modo que eles vêm se tornando cada vez mais populares entre os arquitetos e designers, principalmente para criação de espaços públicos temporários. Com essa tendência em alta, juntamente com o desenvolvimento de novos componentes, é possível esperar um crescimento ainda maior do uso e experimentação desse material, tanto para as edificações temporárias quanto para edificações permanentes, de forma que, em um futuro próximo, os andaimes possam se consolidar como um tipo de sistema construtivo mais difundido.

O grande desafio para os arquitetos é resolver uma boa integração entre os componentes-padrões do andaime e os outros elementos construtivos, principalmente os fechamentos, esquadrias e cobertura, que ainda são pouco 
desenvolvidos pela indústria, pelo fato de ainda não existir demanda de consumo suficiente para viabilizar uma pesquisa e produção desses elementos.

Também fica constatado que o grande trunfo do andaime, como solução construtiva, é a sua flexibilidade em geral. O sistema foi criado para ser montado e desmontado de forma mais eficiente que outros métodos construtivos. Se esse conceito não for importante para projeto, a escolha pelo andaime como estrutura principal pode não se sustentar. Além disso, há também a opção por conceituar o produto como autoconstrução ou por enfatizar o aspecto industrial que essas estruturas proporcionam.

E, por fim, percebe-se uma tendência imediata em pensar que o andaime é obrigatoriamente um material barato, quando na verdade há uma diversidade tão grande de qualidade, modelos e soluções disponíveis, que torna possível atuar em várias faixas de preços. As estruturas de andaimes possuem um campo vasto para estudos e desenvolvimento de projetos futuros, tanto em termos arquitetônicos, que exploram as novas aplicações quanto em termos tecnológicos que aperfeiçoam o produto para o canteiro de obras e criam novos componentes complementares para o sistema. O cenário ideal para esses estudos é um ambiente multidisciplinar, em que a arquitetura e a engenharia caminhem juntas, chegando a ser complementares e quase 
coincidentes nas buscas de resultados.

\section{Referências}

CG SISTEMAS. Vigas de escoramentos H20, Suzano (São Paulo). CG SISTEMAS. Disponível em: <http://cgsistemas.ind.br/>. Acesso em: 20 nov. 2017.

HELBIG, T.; JUNGJOHANN, H.; OPPE, M. The return of modular construction - the adaptation of scaffolding to form the load-bearing structures of buildings. Detail, Munique, n. 10, p. 1127-1134, 2013.

KRONENBURG, R. Flexible: architecture that responds to change. Londres: Laurence King, 2007.

MARKS, M. Scaffolding - The handbook for estimating and product knowledge. 1 ${ }^{\text {a }}$. ed. [S.I.]: Page Publishing, 2016.

MOURNING, T. Architecture (or idea) as drawing. Scaffold and lace, 2016. Disponível em: <https://goo.gl/4Vbmnm>. Acesso em: 05 fev. 2017.

O'NEILL, P. The Blue House. Jeanne works, 2009. Disponível em: <https://goo.gl/eh9m3A>. Acesso em: nov. 2017.

RAMOS FILHO, J. D. M. Andaimes - Tecnologia europeia.

Florianópolis: Insular, 2012.

VIUNOV, V. Comparison of scaffolding systems in Finland and in Russia. Saimaa University of Applied Sciences: Lappeenranta, 2011. 
